\title{
An Analytical Framework for Classifying Software Tools and Systems Dealing with Cultural Heritage Spatio-Temporal Information
}

\author{
Andrea Luczfalvy Jancsó, Benoît Jonlet, Patrick Hoffsummer, \\ Emmanuel Delye and Roland Billen
}

\begin{abstract}
This paper presents an analytical framework for classifying software tools and systems dealing with spatio-temporal information developed for applications in the cultural heritage field. These can be numerous and quite different from one another, depending for the purpose they were developed for. In order to assess if one of the already existing software tools and systems can be used or modified to fit our research goals, a list of needs was established. Starting from those, requirements were defined and the software tools and systems dealing with spatio-temporal information are then compared and evaluated based on those characteristics. This analytical framework is an important step in our research since using a tool that is not appropriate for the study object will not be able to provide valuable information to answer the main research questions.
\end{abstract}

Keywords Analytical framework - Spatio-temporal information - Cultural heritage • Medieval castles • 3D point clouds • Semantics

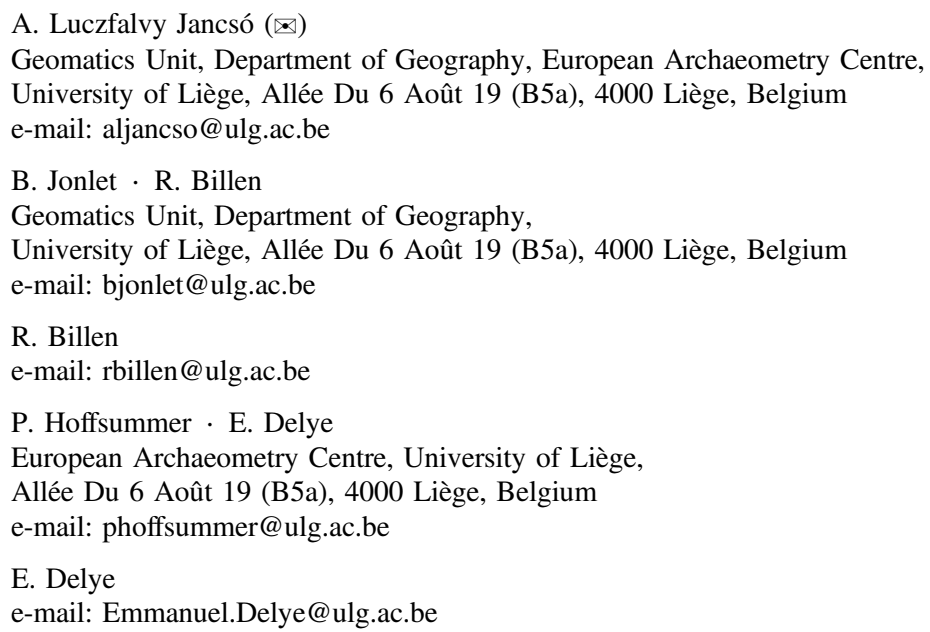




\section{Introduction}

For the study of a series of medieval castles located around the city of Liège in the east of Belgium, an archaeomatic approach using technology such as 3D laser scanner and information systems was chosen. Through this application, we strive to deepen our understanding of their history, the reciprocal influence between the fortress and their respective landscape as well as the stakes that were involved in the choice of their location and the defence of those cultural heritage sites.

As for the available data on those castles, it comes in various forms, such as textual testimonies and visual documents, e.g. prints, wash drawings, photographs from different periods and ancient postcards. Additionally, during the past century, studies and excavations have been conducted on site according to the methodologies of those times. Therefore, the state of the documentation linked to those interventions can be inconsistent, insufficient or even missing. In addition to this, every castle in this research is in a different conservation state and the data available for each site differs in quality and quantity.

As stated in Luczfalvy Jancsó et al. (2016), a 3D point cloud will serve as a base for the current research. Acquired by lasergrammetry and photogrammetry, these 3D models are objective digitisations that will be completed with the already existing data in order to obtain new information to further the knowledge about medieval castles from Belgium and northeastern France as well as the relationship between them and their physical environment.

\section{Assessing Our Needs and Requirements}

The starting point of our research is a 3D digitisation of every one of the study objects. This leads to the necessity to use a software tool or a system that supports not only the integration of a 3D point cloud, but that also allows to interact with it, be it through segmentation or adding data to those parts (Luczfalvy Jancsó et al. 2016). Therefore, in order to deal with the three dimensional data, it is required that the software tool or system provides a 3D input.

As these cultural heritage sites date back to the Middle Ages, the architecture mostly does not follow any standards or symmetry. The understanding of their architectural history is complicated through the frequent modifications and repair works. The identification of the different construction and/or destruction phases is the key to tell the story of those cultural heritage sites since for most of them, there are rarely testimonies with concrete information on the various interventions that the castle underwent. These temporal and spatial characteristics have to be taken into consideration and managed by the software tool or the system selected for this research. Therefore, as already mentioned in Luczfalvy Jancsó et al. (2016), the software tool or the system has to be able to cope with all the particularities of an archaeological research, such as the multivocality (Cripps 2013; 
Luczfalvy Jancsó et al. 2016) that concerns both the spatial and the temporal components and such as the uncertainty, imprecision, ambiguity and incompleteness of archaeological data (De Runz 2008; Luczfalvy Jancsó et al. 2016). Temporality also has to cope with the fuzziness inherent to this discipline (Belussi and Migliorini 2014, 2017; De Roo et al. 2013a, Luczfalvy Jancsó et al. 2016).

These features also intervene when dealing with past excavations. Some of those sites have been subjected on and off to archaeological digs executed by various directors over the course of the last 100 years. These have been documented to the best of their periods, techniques and methodologies. However, archaeological techniques have evolved quite a bit during the second half of the last century, which is mostly due to new technical possibilities, to the joint work between different disciplines of the science and the humanities sectors and to the development of new research interests. Additionally to the missing information that was not deemed necessary at the time or that were not uncovered the same way that nowadays excavations and recording techniques would, the data resulting from those past digs is not always available as it could have been lost, never been published or not even brought to paper if the operations director did not do so. Added to other data sources, such as texts or images, all of these different document types, also taking into account the particularities of archaeological data, need a semantic framework allowing linking them with the 3D model.

Moreover, those past excavations are not always part of the 3D digitisation as the trenches have sometimes been backfilled. Only plans, cross-sections and photographs can be used to analyse those sections. Therefore, the software tool or the system needs to include some 3D modelling/reconstruction possibilities. This could be helpful for the understanding of conclusions and results from those ancient studies. This would also be beneficial to the spatial understanding of this underground, inaccessible and lost evidence due to the destructive nature of archaeological research. The spatial relocation of the findings could also be helpful to verify the chronology that has been established based on the stratigraphic evidence.

As the research currently being carried out deals with the castles and their surrounding territories, it is not always necessary that every detail available is also accessed. Indeed, be it minor architectural decorations and some internal building elements that have no impact on the relationship between the landscape and the cultural heritage site or on a construction volumes analysis do not have to be visible. Also, the documentation that is specifically linked to them does also not have to accessible, as they would not provide relevant information. To limit the visualization of the 3D model and the data access, the integration of Levels of Details (LoD) would be an interesting feature. This way, each LoD could be defined in order to provide the needed visual support and documentation for specific studies.

The software tool or system dealing with spatio-temporal information for our research should be able to handle large 3D point clouds as well as spatial, temporal and semantical aspects. As archaeological data consists of different supports, in digital or physical form, the import function should allow for multiple file formats to be inserted into the software tool or the system. The storage must also be thought 
of as the 3D point cloud on its own already weighs quite a lot and the rest of the data can vary from only a few to a great number of documents. The export format should also be chosen in order to permit for interoperability with other softwares and tools.

\section{Requirements Definition}

In order to evaluate the usefulness of existing software tools and systems dealing with spatio-temporal information, we have determined a series of requirements. They are linked to the needs we have previously established.

General Approach This first item is less a requirement than basic information about the main components of the software tool or the system. This gives a first indication of the features that will be included. In the Table 1, it seems that the general approach is often based on one of these three possibilities: database, GIS and CAD/BIM.

3D Input The 3D input is vital to our research as a 3D digitisation is our primary working tool for the study of each of the castles. If such an input is possible, it is also interesting to list the actions that can be undertaken on the 3D model such as the opportunity to take measurements, to model and/or reconstruct missing parts.

Spatiality This is one of the key features while working with cultural heritage objects and their environment. They are characterised by their location, their dimensions and their volumes. This entry has been divided into three subparts: vector, raster, 3D point cloud. This separation has been added since all three kinds of spatial representation are not always taken into consideration by the various software tools and systems. For the vector entry, a difference is marked by adding the information if the data is structured or not. This means to differentiate the spatial data that only is provided with a geometric model, in contrast to the spatial data that is also structured with topological information. This difference does not apply to raster data as it consists of georeferenced imagery. As research on 3D point clouds is not currently far enough to apply topological structures, we are limited to indicate if the software tools and systems support the integration of 3D point clouds. The possibility to add vector, raster or 3D point cloud data will affect storage, querying and analysis, further down during the investigations.

Spatial Standard The use of standards or not can infer on the interoperability with other softwares and systems and as well as provide a common ground for every researcher involved with the study.

Temporality Temporality can be approached in different ways, such as an attribute in the database or through phasing the visual support with different versions of a same 3D model with or without attributes. It is however not excluded that another possibility exists to integrate a temporal feature. Indeed, as the temporal feature is one of the most complicated aspects to handle in such a software or system since it is not always an absolutely defined date and it might be subject to fuzziness and changes (Belussi and Migliorini 2014; Belussi and Migliorini 2017; 


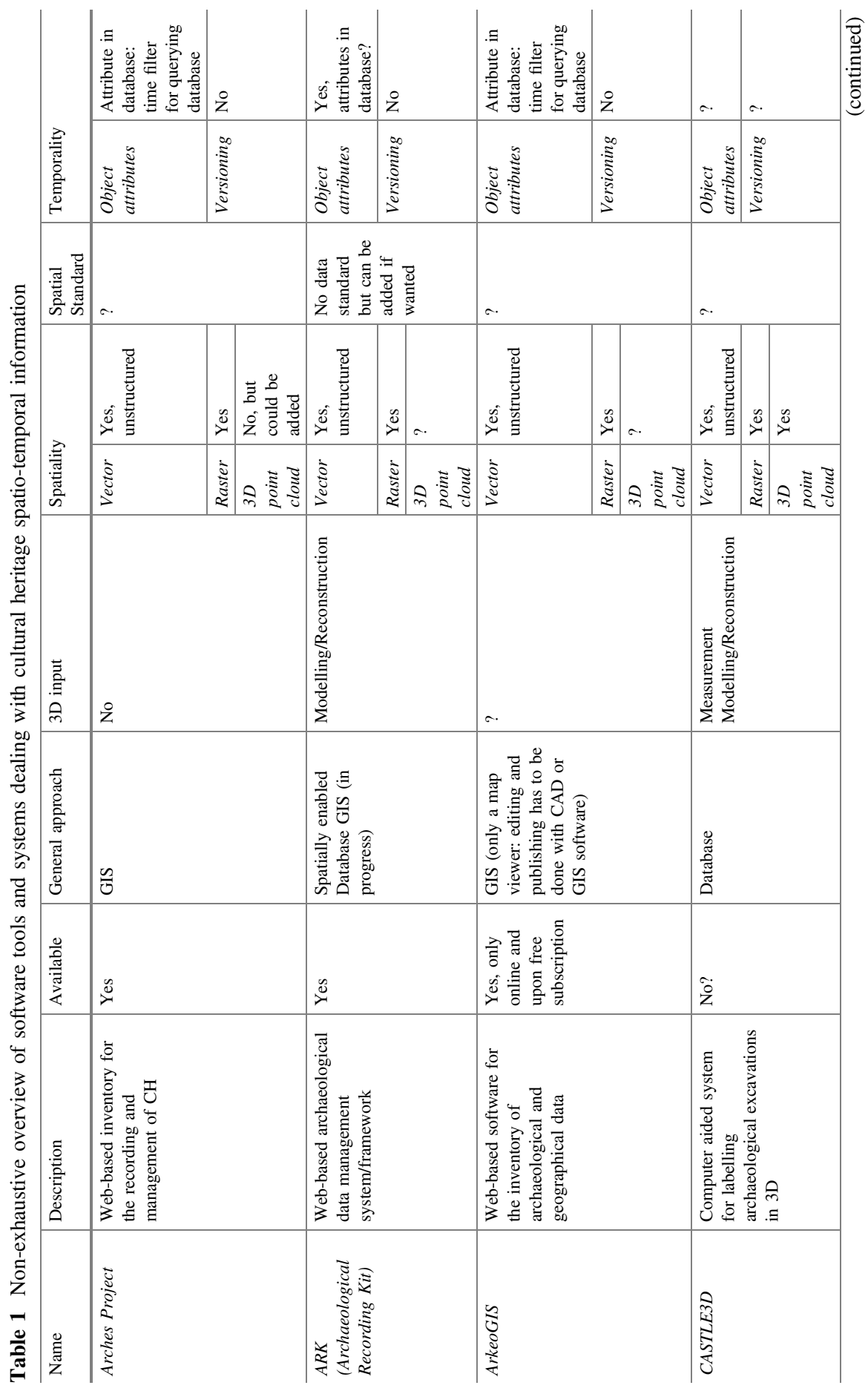




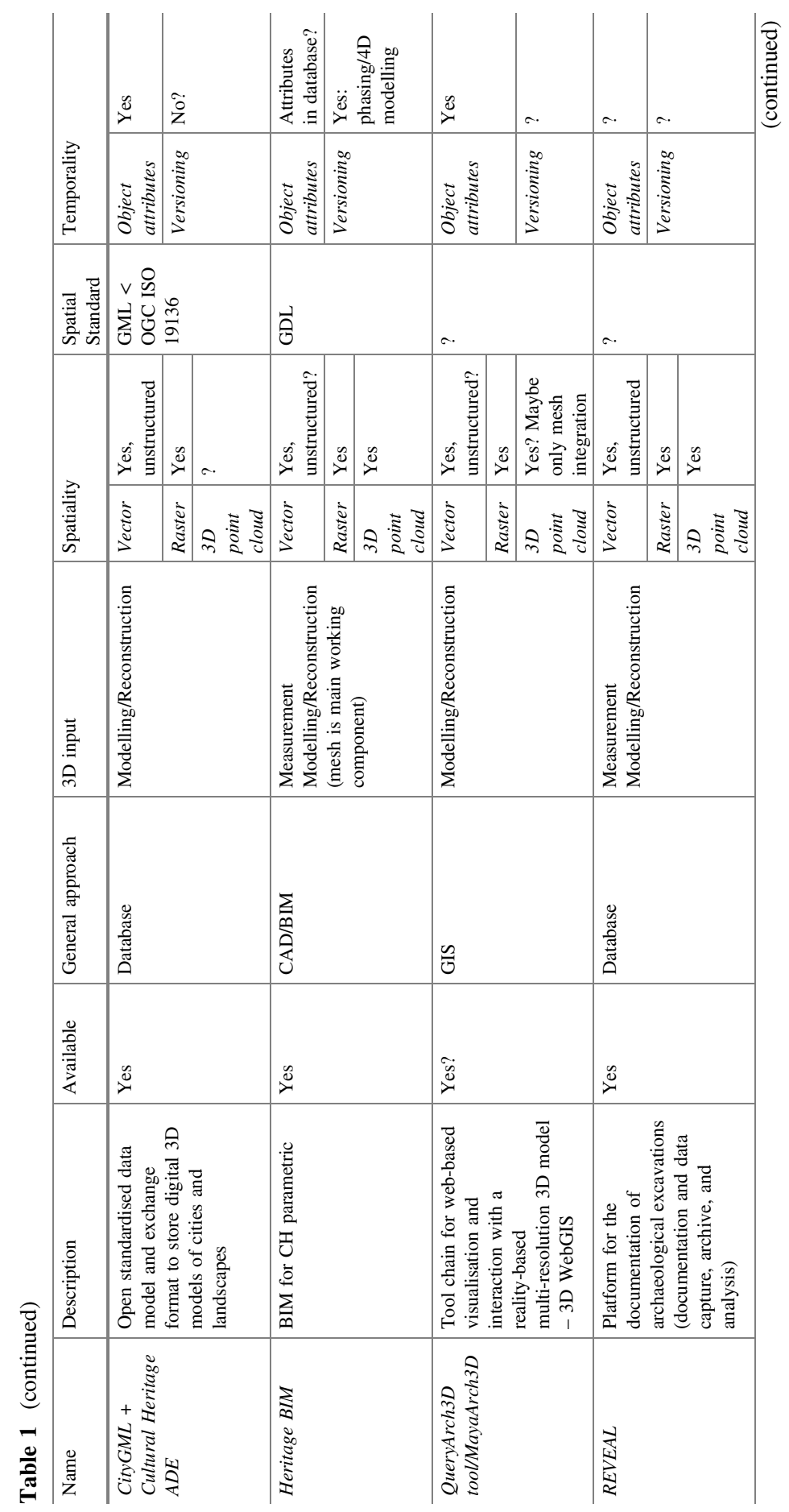




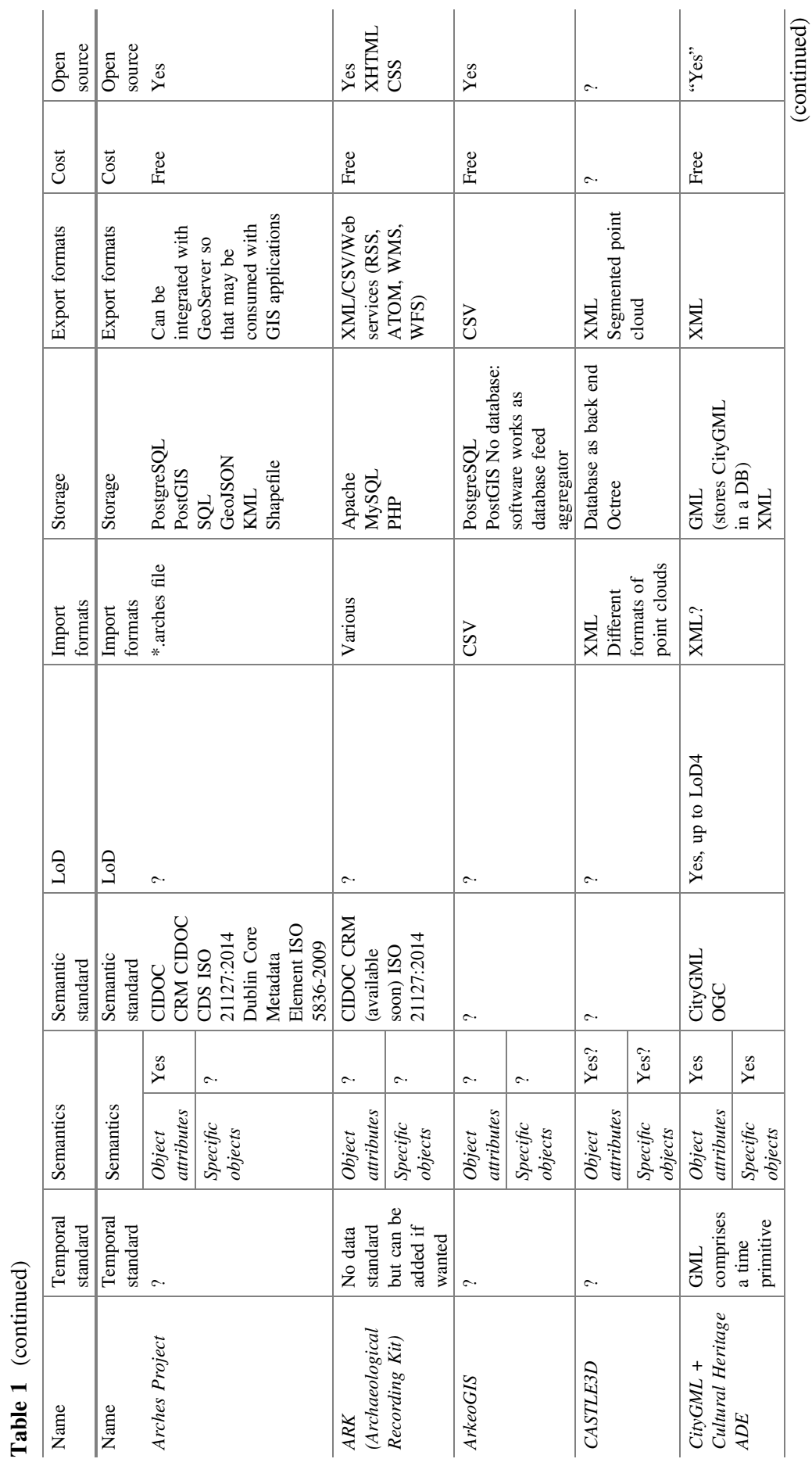


A. Luczfalvy Jancsó et al.

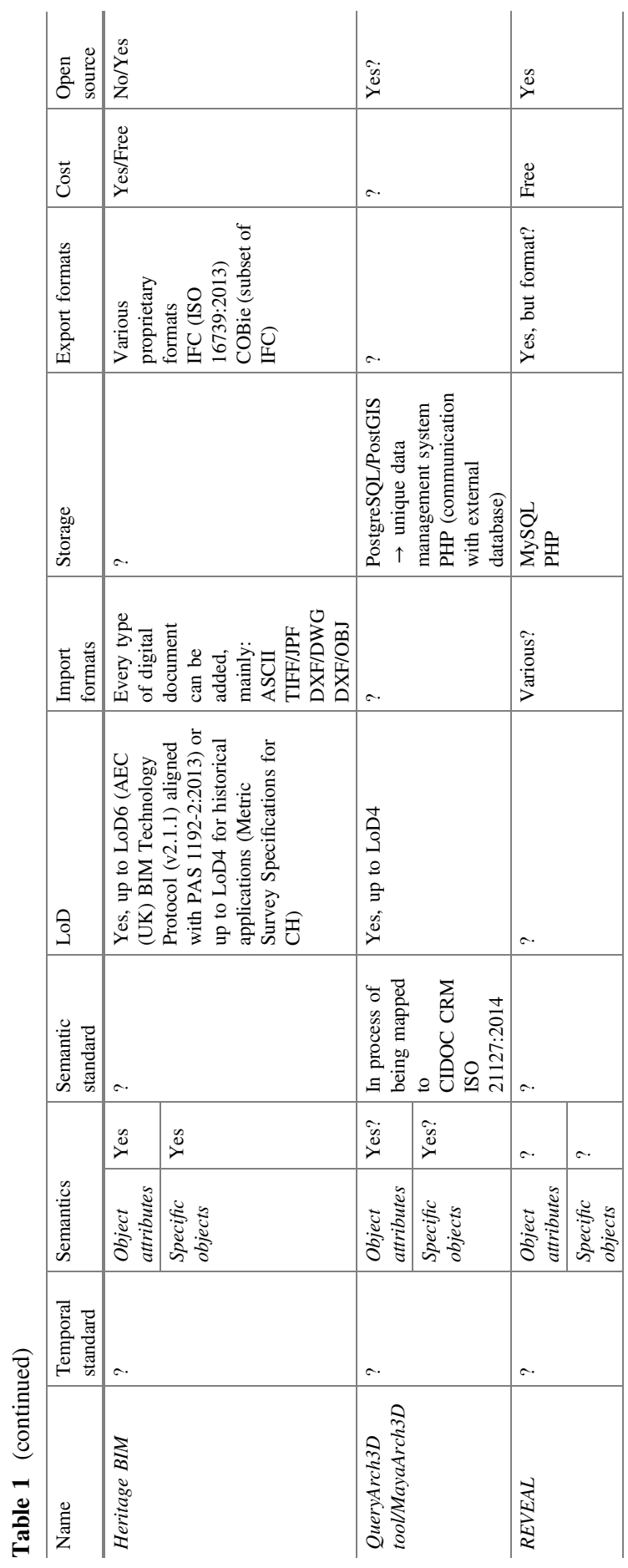


De Roo et al. 2013b; Katsianis et al. 2008). Also, as the authors in (Katsianis et al. 2008) state, up to six time categories can be considered. Some standards have been developed but not every software or system relies on them.

Temporal Standard The use of a standard for the temporal component would be of help to assure interoperability and comparison between the different study objects. However, it will have to be verified if the used standard can be correctly applied to each case.

Semantics As the 3D model is meant to be the interface through which the available data will be accessed and queried, it is necessary to integrate a semantic framework that will be used as basis to combine archaeological data and sources with the 3D point clouds. A difference can be made between attributes that link to an object, such as a polygon linked to a function, or specific objects that are linked to each other in order to create a semantic model.

Semantic Standard The semantic standard that is the most used is the CIDOC CRM (ICOM's International Committee for Documentation Conceptual Reference Model) which is based on the ISO 21127:2014 standard. The CIDOC CRM standard provides a common ground for the description and integration of the various types of cultural heritage data into information systems and conceptual models (http://www.cidoc-crm.org/). However, based on the type of semantic that is incorporated into the software tool or system, other standards can also be considered.

Level of Detail (LoD) Depending on the current research goal, it is not always necessary to render all of the details of the $3 \mathrm{D}$ model. Therefore, working with LoDs can be taken into consideration. However, each used LoD repartition differs from one system to another: the specificities of each level as well as the number of levels can vary.

Import/Export Formats The import and export file types cover a wide range of possibilities. Some of the export formats follow international standards.

Storage The storage is mostly handled through databases. The spatial component is sometimes managed separately from the rest of the data. This feature will impact the way the data is accessed and the actions and queries the data could be subjected to.

Cost/Open Source Additionally, even if this point does not directly answer the previously mentioned needs, it can provide useful information on the adaptability and the interoperability of the software tool or the system as well as the financial impact as the cost can greatly impact the integration of these softwares and systems as a research tool. The open source working allows for the addition of extensions and plugins that managed needed aspects, which are not taken care of by starting pack of the software or the system. 


\section{Some Existing Software Tools and Systems Dealing with Cultural Heritage Spatio-Temporal Information}

Once our needs have been ascertained and the requirements established, a first non-exhaustive list of software tools and systems dealing with cultural heritage spatio-temporal information was established.

The Arches Project This system (Carlisle et al. 2014; http://archesproject.org/; Myers et al. 2016) was developed by the Getty Conservation Institute and the World Monuments Fund as an inventory and management tool for cultural heritage.

ARK (Archaeological Recording Kit) This collection of tools (http://ark. lparchaeology.com/) is destined for the "collection, storage and dissemination of archaeological data".

ArkeoGIS This software compiles archaeological and environmental data (http://arkeogis.org/fr/arkeogis-de-lhypothese-a-la-carte/; Bernard et al. 2015).

CASTLE3D CASTLE3D stands for Computer Aided System for Labelling Archaeological Excavations in 3D (Houshiar et al. 2015; Nuechter et al. 2015). This system focuses on the recording of archaeological evidence.

CityGML with the Cultural Heritage ADE CityGML (https://www.citygml. org/ade/; https://www.citygml.org/; http://www.3dcitydb.org/3dcitydb/ 3dcitydbhomepage/) is a data model as well as an exchange format. It deals with 3D models of cities and landscapes. An Application Domain Extension (ADE) (Costamagna and Spanò 2013; De Roo et al. 2014; Finat et al. 2010) has been developed specifically for cultural heritage means. Combined with basic CityGML, it is better suited for the specificities of an archaeological research.

Heritage BIM This is a BIM version that is better adapted for the work on a cultural heritage site (Antonopoulou 2017; Chiabrando et al. 2016).

QueryArch3D Tool/MayaArch3D This tool (Agugiaro et al. 2011; http://www. mayaarch3d.org/language/en/sample-page/) allows to visualize and to query multiresolution 3D models.

REVEAL The acronym stands for Reconstruction and Exploratory Visualization: Engineering meets ArchaeoLogy (Sanders 2011; http://ark.lparchaeology. $\mathrm{com} /$ ). It is a software that helps with the documentation recording process of an archaeological excavation as well as with the analysis of this data.

Although this list might be non exhaustive and the analysed software tools and systems were primarily chosen based on their ability to integrate $3 \mathrm{D}$ data as well as on their availability for testing, this first try allows us to verify if some potentially interesting working tools already exist. Additionally, we had the opportunity to develop an analytical framework based on our previously established requirements for an information system that fits our research.

In order to evaluate the usefulness of these existing software tools and systems, the previously determined requirements based on the needs discussed in the first part of this paper were applied to each of the selected software tools and systems. 
Indeed, each of them was entered into the Table 1 to get a better overview of their characteristics and to facilitate comparisons between them. Currently, the entries into the table are provisional as the framework has been set, but the analysis is still ongoing.

As we have tested those existing software tools and systems against our requirements, it is obvious that some cells are left blank. Currently, we preferred to add a question mark instead of leaving an empty unit. This decision was made because the absence of information about a specific entry does not necessarily mean that this characteristic is not supported by the software or the system. However, it may not be mentioned in the software or system description as it does not have an impact on its use and its smooth running. Also, although the content added in the storage column does not always directly relate to it, we decided to maintain it there as these entries provide information on how the data will be accessed. If deemed necessary, a new section regarding the main technologies and programming tools will be added. However, as we did not define a requirement for a specific technology or programming tool, it should be considered as a descriptive column.

\section{Conclusion}

With our requirements in mind for the study of a series of medieval castles, this analytical framework provides a sound basis to compare the different available software tools and systems dealing with cultural heritage spatio-temporal information.

In order to complete some of the missing information in the table cells, some trials are probably the best way to provide precise information about some of those requirements.

These preliminary results show that some softwares or systems (e.g. CityGML with the cultural heritage ADE, the QueryArch3D tool and the Heritage BIM) seem to be the most appropriate since they fulfil most of our requirements. However, even if at first glance they seem the most suited, a test drive will also be necessary to assess their actual usefulness. Additionally, these tests will also be the opportunity to check if they are able to cope with the particularities of a medieval building structure as well as with those sections for with there is no $3 \mathrm{D}$ digitisation available, e.g. the ancient excavations that have been backfilled.

Further research will also be carried out to complete the table with other approaches, this time providing an exhaustive list and a state-of-the-art of the existing software tools and systems dealing with spatio-temporal information for cultural heritage. 


\section{References}

3D Geoinformation group at TU Delft: Application Domain Extensions (ADE). https://www. citygml.org/ade/

3D Geoinformation group at TU Delft: CityGML homepage. https://www.citygml.org/

Agugiaro $G$ et al (2011) QueryArch3D: querying and visualising 3D models of a maya archaeological site in a web-based interface. Geoinform FCE CTU 6:10-17

Antonopoulou S (2017) BIM for heritage: developing a historic building information model

L-P Archaeology - ARK. An open source solution to project recording. http://ark.lparchaeology. $\mathrm{com} /$

ArkéoGIS. http://arkeogis.org/fr/arkeogis-de-lhypothese-a-la-carte/

Belussi A, Migliorini S (2014) A framework for managing temporal dimensions in archaeological data. In: Cesta A et al (eds) Proceedings of the 2014 21st international symposium on temporal representation and reasoning. IEEE, pp 81-90

Belussi A, Migliorini S (2017) A spatio-temporal framework for managing archeological data. Ann Math Artif Intell 80:175-218

Bernard L et al (2015) ArkeoGIS, merging geographical and archaeological datas online. In: Giligny $\mathrm{F}$ et al (eds) CAA2014, 21st century archaeology: concepts, methods and tools: proceedings of the $42 \mathrm{nd}$ annual conference on computer applications and quantitative methods in archaeology. Archaeopress, Oxford, pp 401-406

Carlisle PK et al (2014) The arches heritage inventory and management system: a standards-based approach to the management of cultural heritage information. In: CIDOC (International Committee for Documentation of the International Council of Museums) conference: access and understanding-networking in the digital era, Dresden, Germany, pp 6-11

Chair of Geoinformatics, Technische Universität München: The CityGML Database. 3D City DB. http://www.3dcitydb.org/3dcitydb/3dcitydbhomepage/

Chiabrando $\mathrm{F}$ et al (2016) Historical buildings models and their handling via 3D survey: from points clouds to user-oriented HBIM. ISPRS-Int Arch Photogramm Remote Sens Spat Inf Sci XLI-B5:633-640

Costamagna E, Spanò A (2013) CityGML for architectural heritage. In: Abdul Rahman A et al (eds) Developments in multidimensional spatial data models. Springer, Berlin, pp 219-237

Cripps P (2013) Places, people, events and stuff; building blocks for archaeological information systems. In: Archaeology in the digital era, vol II. e-Papers from the 40th annual conference of computer applications and quantitative methods in archaeology (CAA), Southampton, 26-29 March 2012. Amsterdam University Press, Amsterdam, pp 487-497

De Roo B et al (2013a) On the way to a 4D archaeological GIS: state of the art, future directions and need for standardization. In: Proceedings of the 2013 digital heritage international congress, pp 617-620

De Roo B et al (2013b) The temporal dimension in a 4D archaeological data model: applicability of the geoinformation standard. ISPRS Ann Photogramm Remote Sens Spat Inf Sci II-2/W1, W1:111-121

De Roo B et al (2014) Bridging archaeology and GIS: Influencing factors for a 4D archaeological GIS. Lect Notes Comput Sci Subser Lect Notes Artif Intell Lect Notes Bioinforma 8740:186195

De Runz C (2008) Imperfection, temps et espace : modélisation, analyse et visualisation dans un SIG archéologique. University of Reims Champagne-Ardenne

Finat $\mathbf{J}$ et al (2010) GIRAPIM. A 3D information system for surveying cultural heritage environments. ISPRS-Int Arch Photogramm Remote Sens Spat Inf Sci XXXVIII-4, W15:107-113

German Archaeological Institute, GIScience Research Group: MayaArch3D_-3D Visulisation and Analysis of Maya Archaeology. http://www.mayaarch3d.org/language/en/sample-page/

Houshiar H. et al (2015) CASTLE3D-a computer aided system for labelling archaeological excavations in 3D. ISPRS Ann Photogramm Remote Sens Spat Inf Sci II-5/W3:111-118 
International council of museums, International committee for documentation: CIDOC CRM. http://www.cidoc-crm.org/

J. Paul Getty Trust. World monuments fund: arches project cultural heritage inventory and management software. http://archesproject.org/

Katsianis $\mathrm{M}$ et al (2008) A 3D digital workflow for archaeological intra-site research using GIS. J Archaeol Sci 35(3):655-667

Luczfalvy Jancsó A et al (2016) CASTLE4D: an archaeological information system based on 3D point clouds. In: Lerma JL, Cabrelles M (eds) Proceedings of the ARQUEOLÓGICA 2.0 8th international congress on archaeology, computer graphics, cultural heritage and innovation. Universitat Politècnica València, Valencia, pp 247-252

Myers D et al (2016) The Arches heritage inventory and management system: a platform for the heritage field. J Cult Heritage Manage Sustain Dev 6(2):213-224

Nuechter A et al (2015) Das Castle3D Framework zur fortlaufenden semantischen 3D-Kartierung von archäologischen Ausgrabungsstätten. Allg Vermess-Nachrichten 06(07):233-247

Sanders DH (2011) Enabling archaeological hypothesis testing in real time using the REVEAL documentation and display system. Virtual Archaeol Rev 2(4):89

The Institute for the Visualization of History: REVEAL-reconstruction and exploratory visualization: engineering meets archaeology. http://www.vizin.org/projects/reveal/setting. html 